\title{
INTONATION: THE STRONGEST LINK IN THE WEAKEST LINK QUIZ
}

\section{INTRODUCTION}

People do not always want to verbalize what they really mean. Instead, they spend time carefully choosing their words and syntactic structures. When they finally utter them, it often happens that the addressees feel that the speakers meant more than their words actually said.

The statement "It wasn't so much what they said, as the way they said it," clearly indicates how strongly people react to intonation. Although they are normally not conscious of different prosodic features that make up intonation as a whole, they are nevertheless very sensitive to it, especially when it runs counter to their expectations. When in a particular context of interaction they hear an unexpected intonation pattern, their first reaction is to search for an implied meaning. If they cannot find it, they may be amused or bewildered and in the extreme example angry or even hurt.

Intonation is an essential part of language study which has linguistic, discourse and pragmatic functions. Its primary linguistic function is to link lexis, grammar and speech. The discourse function of intonation is to explore ways of achieving cohesion in spoken discourse, whereas its pragmatic function is to enable the hearer to make inferences from the utterance's context in order to enrich the interpretation. In other words, intonation does not alter the sense of lexical items, it merely shades their meanings by providing the hearer with an opportunity to choose between different interpretations at the lexico-syntactic level dependent on the context of interaction.

The linguistic function of intonation is probably least elusive as it works hand in hand with syntax and is as such concerned with the organization of the message (e.g. old/new information, the number of pieces of information, the completeness or incompleteness of the message) as well as with its mode (e.g. indicative, imperative and subjunctive). The linguistic function is expressed by means of two processes: tonality which is concerned with the division of speech into intonation units, and tonicity which deals with the focal point of intonation. In a language like English which has a fairly fixed word order which does not allow the sentence elements to change places randomly without changing the meaning of the message - it is fairly easy to make tonality and tonicity rules. And indeed, linguists have been successful in doing that. Halliday (1976), who tried to link grammar and intonation, fully developed the notions of neutral and marked tonality and tonicity and established by which prosodic features they are expressed in spoken discourse.

* Author's address: Filozofska fakulteta, Oddelek za anglistiko in amerikanistiko, Aškerčeva 2, 1000 Ljubljana, Slovenia. Email: smiljana.komar@guest.arnes.si 
The discourse function of intonation does not concern so much the syntax as it does the relationship between the interlocutors, on the one hand, and between the speaker and the message, on the other. Conversation analysis, which generally observes the speakers' behaviour in the turn-taking strategies, tries to find prosodic means which the participants in a spoken interaction employ to signal different degrees of cooperativeness or uncooperativeness. Important work on the function of different prosodic features in conversation and in particular in turn-taking was done by Couper-Kuhlen (1986, 1993) and Couper-Kuhlen and Selting (1996). They illustrated how intonation reflects the orderly, as well as in orderly turn-taking and supportive, as well as non-supportive backchannelling.

Another aspect of the discourse function of intonation concerns cohesion. Although it is generally believed that cohesive ties are realized by different grammatical and lexical references, it is plausible to claim that different prosodic features may play an equally important role in achieving cohesion in spoken discourse. The pioneering and seminal work was carried out by Brazil (1997) who established that the prosodic features of 'tone', 'key' and 'termination' play an important part in expressing cohesion in speech. The 'referring' tones (i.e. the fall-rise, the rise) are to express the anaphoric reference to everything that is shared by the interlocutors, whereas the 'proclaiming' tones (i.e. the fall, the rise-fall) are usually used to express cataphoric reference, i.e. to introduce new information. Key and termination are used to establish contrastive or equivalent meaningful relations between two pieces of information where the high key is used to express the former and the mid key the latter. The function of termination is primarily to limit and predict the addressee's response: the high termination is said to encourage further conversation, while the low termination indicates the possible end of conversation.

The pragmatic function of intonation is by far most elusive and difficult to describe. It concerns the relationship between the speaker meaning and the surface meaning of an utterance which is very context-dependent. Speakers, when they find out that there is a mismatch between the content of an utterance and the context in which it is conveyed, are usually bewildered. The same may happen when they realise that there is a disagreement between the intonation of the message and the context in which it is delivered.

The pragmatic function of intonation has been the preoccupation of a number of renowned linguists (Crystal/Davy, 1975, O’Connor/Arnold, 1975) who have tried to establish the predicted attitudinal meanings of intonation in a particular context. The result was a mass of different labels, each referring to a different attitude or emotion. The terms 'attitude' and 'emotion' were often used synonymously, thus causing even greater disorder. Couper-Kuhlen (1986: 185-7) has suggested a distinction between emotion and attitude. For her 'emotion' is a speaker's state of being (e.g. happy, sad, angry etc.) whereas 'attitude' refers to a kind of behaviour (e.g. being friendly, kind, condescending etc). Wichmann (2000: 145) has argued that there are some attitudes which cannot fall in the category of behaviour but are better described as opinions, beliefs or knowledge about something (e.g. being critical of, 


\section{INTONATION: THE STRONGEST LINK IN THE WEAKEST LINK QUIZ}

\section{INTRODUCTION}

People do not always want to verbalize what they really mean. Instead, they spend time carefully choosing their words and syntactic structures. When they finally utter them, it often happens that the addressees feel that the speakers meant more than their words actually said.

The statement "It wasn't so much what they said, as the way they said it," clearly indicates how strongly people react to intonation. Although they are normally not conscious of different prosodic features that make up intonation as a whole, they are nevertheless very sensitive to it, especially when it runs counter to their expectations. When in a particular context of interaction they hear an unexpected intonation pattern, their first reaction is to search for an implied meaning. If they cannot find it, they may be amused or bewildered and in the extreme example angry or even hurt.

Intonation is an essential part of language study which has linguistic, discourse and pragmatic functions. Its primary linguistic function is to link lexis, grammar and speech. The discourse function of intonation is to explore ways of achieving cohesion in spoken discourse, whereas its pragmatic function is to enable the hearer to make inferences from the utterance's context in order to enrich the interpretation. In other words, intonation does not alter the sense of lexical items, it merely shades their meanings by providing the hearer with an opportunity to choose between different interpretations at the lexico-syntactic level dependent on the context of interaction.

The linguistic function of intonation is probably least elusive as it works hand in hand with syntax and is as such concerned with the organization of the message (e.g. old/new information, the number of pieces of information, the completeness or incompleteness of the message) as well as with its mode (e.g. indicative, imperative and subjunctive). The linguistic function is expressed by means of two processes: tonality which is concerned with the division of speech into intonation units, and tonicity which deals with the focal point of intonation. In a language like English which has a fairly fixed word order which does not allow the sentence elements to change places randomly without changing the meaning of the message - it is fairly easy to make tonality and tonicity rules. And indeed, linguists have been successful in doing that. Halliday (1976), who tried to link grammar and intonation, fully developed the notions of neutral and marked tonality and tonicity and established by which prosodic features they are expressed in spoken discourse.

* Author's address: Filozofska fakulteta, Oddelek za anglistiko in amerikanistiko, Aškerčeva 2, 1000 Ljubljana, Slovenia. Email: smiljana.komar@guest.arnes.si 


\section{INTONATION: THE STRONGEST LINK IN THE WEAKEST LINK QUIZ}

\section{INTRODUCTION}

People do not always want to verbalize what they really mean. Instead, they spend time carefully choosing their words and syntactic structures. When they finally utter them, it often happens that the addressees feel that the speakers meant more than their words actually said.

The statement "It wasn't so much what they said, as the way they said it," clearly indicates how strongly people react to intonation. Although they are normally not conscious of different prosodic features that make up intonation as a whole, they are nevertheless very sensitive to it, especially when it runs counter to their expectations. When in a particular context of interaction they hear an unexpected intonation pattern, their first reaction is to search for an implied meaning. If they cannot find it, they may be amused or bewildered and in the extreme example angry or even hurt.

Intonation is an essential part of language study which has linguistic, discourse and pragmatic functions. Its primary linguistic function is to link lexis, grammar and speech. The discourse function of intonation is to explore ways of achieving cohesion in spoken discourse, whereas its pragmatic function is to enable the hearer to make inferences from the utterance's context in order to enrich the interpretation. In other words, intonation does not alter the sense of lexical items, it merely shades their meanings by providing the hearer with an opportunity to choose between different interpretations at the lexico-syntactic level dependent on the context of interaction.

The linguistic function of intonation is probably least elusive as it works hand in hand with syntax and is as such concerned with the organization of the message (e.g. old/new information, the number of pieces of information, the completeness or incompleteness of the message) as well as with its mode (e.g. indicative, imperative and subjunctive). The linguistic function is expressed by means of two processes: tonality which is concerned with the division of speech into intonation units, and tonicity which deals with the focal point of intonation. In a language like English which has a fairly fixed word order which does not allow the sentence elements to change places randomly without changing the meaning of the message - it is fairly easy to make tonality and tonicity rules. And indeed, linguists have been successful in doing that. Halliday (1976), who tried to link grammar and intonation, fully developed the notions of neutral and marked tonality and tonicity and established by which prosodic features they are expressed in spoken discourse.

* Author's address: Filozofska fakulteta, Oddelek za anglistiko in amerikanistiko, Aškerčeva 2, 1000 Ljubljana, Slovenia. Email: smiljana.komar@guest.arnes.si 
The discourse function of intonation does not concern so much the syntax as it does the relationship between the interlocutors, on the one hand, and between the speaker and the message, on the other. Conversation analysis, which generally observes the speakers' behaviour in the turn-taking strategies, tries to find prosodic means which the participants in a spoken interaction employ to signal different degrees of cooperativeness or uncooperativeness. Important work on the function of different prosodic features in conversation and in particular in turn-taking was done by Couper-Kuhlen (1986, 1993) and Couper-Kuhlen and Selting (1996). They illustrated how intonation reflects the orderly, as well as in orderly turn-taking and supportive, as well as non-supportive backchannelling.

Another aspect of the discourse function of intonation concerns cohesion. Although it is generally believed that cohesive ties are realized by different grammatical and lexical references, it is plausible to claim that different prosodic features may play an equally important role in achieving cohesion in spoken discourse. The pioneering and seminal work was carried out by Brazil (1997) who established that the prosodic features of 'tone', 'key' and 'termination' play an important part in expressing cohesion in speech. The 'referring' tones (i.e. the fall-rise, the rise) are to express the anaphoric reference to everything that is shared by the interlocutors, whereas the 'proclaiming' tones (i.e. the fall, the rise-fall) are usually used to express cataphoric reference, i.e. to introduce new information. Key and termination are used to establish contrastive or equivalent meaningful relations between two pieces of information where the high key is used to express the former and the mid key the latter. The function of termination is primarily to limit and predict the addressee's response: the high termination is said to encourage further conversation, while the low termination indicates the possible end of conversation.

The pragmatic function of intonation is by far most elusive and difficult to describe. It concerns the relationship between the speaker meaning and the surface meaning of an utterance which is very context-dependent. Speakers, when they find out that there is a mismatch between the content of an utterance and the context in which it is conveyed, are usually bewildered. The same may happen when they realise that there is a disagreement between the intonation of the message and the context in which it is delivered.

The pragmatic function of intonation has been the preoccupation of a number of renowned linguists (Crystal/Davy, 1975, O’Connor/Arnold, 1975) who have tried to establish the predicted attitudinal meanings of intonation in a particular context. The result was a mass of different labels, each referring to a different attitude or emotion. The terms 'attitude' and 'emotion' were often used synonymously, thus causing even greater disorder. Couper-Kuhlen (1986: 185-7) has suggested a distinction between emotion and attitude. For her 'emotion' is a speaker's state of being (e.g. happy, sad, angry etc.) whereas 'attitude' refers to a kind of behaviour (e.g. being friendly, kind, condescending etc). Wichmann (2000: 145) has argued that there are some attitudes which cannot fall in the category of behaviour but are better described as opinions, beliefs or knowledge about something (e.g. being critical of, 
being impressed by). Thus she distinguishes between 'expressive' and 'attitudinal' intonation. The first reflects emotions, as well as, opinions, beliefs and knowledge about something or somebody. The second reflects speakers' behaviour as intended by them, or perceived by the addressees, or both.

\section{THE DISCOURSE AND PRAGMATIC FUNCTIONS OF INTONATION IN THE WEAKEST LINK QUIZ}

The Weakest Link quiz, which is with a huge success regularly broadcast on $\mathrm{BBC}$ Prime, was chosen for the analysis of the discourse and pragmatic functions of intonation in English. The quiz is an endurance test characterized by Anne Robinson's putdowns and bitter and sarcastic chats with the contestants, who embarass themselves by providing preposterous answers and stab each other in the back as they vote off their rivals. The show exploits the darkest corners of the human nature and language plays the main role.

The Weakest Link quiz has a strictly defined structure in which the dominant role is played by the hostess, Anne Robinson, who asks questions and evaluates the answers as right or wrong. The other participants in the quiz are nine contestants whose aim is to answer correctly as many questions as possible and bank as much money as they can. The quiz is divided into eight rounds. After each round the contestants have to decide who among them deserves to be voted off as the weakest link. The choice need not always follow the reality, especially towards the end of the quiz when the players strategically get rid of sometimes better players than themselves. In the end only two contestants remain and they have to play against each other in order to win the money that has been banked throughout the show. After each round the hostess spends some time chatting with the contestants. The purpose of this is to belittle and make fun of the contestant in question thus putting at risk their self-confidence. Anne Robinson has made her fame by being truly sarcastic, nasty and rude.

The relations among the participants in the quiz are strictly defined. The dominant speaker par excellence is Anne Robinson and if anyone of the contestants tries to endanger her dominant role, they are immediately punished by one of Anne's caustic remarks. When it comes to the relationships among the contestants, they are clearly subordinate in relation to Anne, but fight for dominance among themselves when Anne gives them the chance to speak and explain why they voted for a particular contestant as the weakest link.

The purpose to use The Weakest Link quiz for the analysis was primarily to show how intonation is used to express dominance, cooperativeness and non-cooperativeness among the contestants, their attitude to the topics of conversation and especially the expressive and attitudinal aspects of their speech which are extremely vital for the success of this show. 
The discourse function of intonation does not concern so much the syntax as it does the relationship between the interlocutors, on the one hand, and between the speaker and the message, on the other. Conversation analysis, which generally observes the speakers' behaviour in the turn-taking strategies, tries to find prosodic means which the participants in a spoken interaction employ to signal different degrees of cooperativeness or uncooperativeness. Important work on the function of different prosodic features in conversation and in particular in turn-taking was done by Couper-Kuhlen (1986, 1993) and Couper-Kuhlen and Selting (1996). They illustrated how intonation reflects the orderly, as well as in orderly turn-taking and supportive, as well as non-supportive backchannelling.

Another aspect of the discourse function of intonation concerns cohesion. Although it is generally believed that cohesive ties are realized by different grammatical and lexical references, it is plausible to claim that different prosodic features may play an equally important role in achieving cohesion in spoken discourse. The pioneering and seminal work was carried out by Brazil (1997) who established that the prosodic features of 'tone', 'key' and 'termination' play an important part in expressing cohesion in speech. The 'referring' tones (i.e. the fall-rise, the rise) are to express the anaphoric reference to everything that is shared by the interlocutors, whereas the 'proclaiming' tones (i.e. the fall, the rise-fall) are usually used to express cataphoric reference, i.e. to introduce new information. Key and termination are used to establish contrastive or equivalent meaningful relations between two pieces of information where the high key is used to express the former and the mid key the latter. The function of termination is primarily to limit and predict the addressee's response: the high termination is said to encourage further conversation, while the low termination indicates the possible end of conversation.

The pragmatic function of intonation is by far most elusive and difficult to describe. It concerns the relationship between the speaker meaning and the surface meaning of an utterance which is very context-dependent. Speakers, when they find out that there is a mismatch between the content of an utterance and the context in which it is conveyed, are usually bewildered. The same may happen when they realise that there is a disagreement between the intonation of the message and the context in which it is delivered.

The pragmatic function of intonation has been the preoccupation of a number of renowned linguists (Crystal/Davy, 1975, O’Connor/Arnold, 1975) who have tried to establish the predicted attitudinal meanings of intonation in a particular context. The result was a mass of different labels, each referring to a different attitude or emotion. The terms 'attitude' and 'emotion' were often used synonymously, thus causing even greater disorder. Couper-Kuhlen (1986: 185-7) has suggested a distinction between emotion and attitude. For her 'emotion' is a speaker's state of being (e.g. happy, sad, angry etc.) whereas 'attitude' refers to a kind of behaviour (e.g. being friendly, kind, condescending etc). Wichmann (2000: 145) has argued that there are some attitudes which cannot fall in the category of behaviour but are better described as opinions, beliefs or knowledge about something (e.g. being critical of, 
being impressed by). Thus she distinguishes between 'expressive' and 'attitudinal' intonation. The first reflects emotions, as well as, opinions, beliefs and knowledge about something or somebody. The second reflects speakers' behaviour as intended by them, or perceived by the addressees, or both.

\section{THE DISCOURSE AND PRAGMATIC FUNCTIONS OF INTONATION IN THE WEAKEST LINK QUIZ}

The Weakest Link quiz, which is with a huge success regularly broadcast on $\mathrm{BBC}$ Prime, was chosen for the analysis of the discourse and pragmatic functions of intonation in English. The quiz is an endurance test characterized by Anne Robinson's putdowns and bitter and sarcastic chats with the contestants, who embarass themselves by providing preposterous answers and stab each other in the back as they vote off their rivals. The show exploits the darkest corners of the human nature and language plays the main role.

The Weakest Link quiz has a strictly defined structure in which the dominant role is played by the hostess, Anne Robinson, who asks questions and evaluates the answers as right or wrong. The other participants in the quiz are nine contestants whose aim is to answer correctly as many questions as possible and bank as much money as they can. The quiz is divided into eight rounds. After each round the contestants have to decide who among them deserves to be voted off as the weakest link. The choice need not always follow the reality, especially towards the end of the quiz when the players strategically get rid of sometimes better players than themselves. In the end only two contestants remain and they have to play against each other in order to win the money that has been banked throughout the show. After each round the hostess spends some time chatting with the contestants. The purpose of this is to belittle and make fun of the contestant in question thus putting at risk their self-confidence. Anne Robinson has made her fame by being truly sarcastic, nasty and rude.

The relations among the participants in the quiz are strictly defined. The dominant speaker par excellence is Anne Robinson and if anyone of the contestants tries to endanger her dominant role, they are immediately punished by one of Anne's caustic remarks. When it comes to the relationships among the contestants, they are clearly subordinate in relation to Anne, but fight for dominance among themselves when Anne gives them the chance to speak and explain why they voted for a particular contestant as the weakest link.

The purpose to use The Weakest Link quiz for the analysis was primarily to show how intonation is used to express dominance, cooperativeness and non-cooperativeness among the contestants, their attitude to the topics of conversation and especially the expressive and attitudinal aspects of their speech which are extremely vital for the success of this show. 
being impressed by). Thus she distinguishes between 'expressive' and 'attitudinal' intonation. The first reflects emotions, as well as, opinions, beliefs and knowledge about something or somebody. The second reflects speakers' behaviour as intended by them, or perceived by the addressees, or both.

\section{THE DISCOURSE AND PRAGMATIC FUNCTIONS OF INTONATION IN THE WEAKEST LINK QUIZ}

The Weakest Link quiz, which is with a huge success regularly broadcast on $\mathrm{BBC}$ Prime, was chosen for the analysis of the discourse and pragmatic functions of intonation in English. The quiz is an endurance test characterized by Anne Robinson's putdowns and bitter and sarcastic chats with the contestants, who embarass themselves by providing preposterous answers and stab each other in the back as they vote off their rivals. The show exploits the darkest corners of the human nature and language plays the main role.

The Weakest Link quiz has a strictly defined structure in which the dominant role is played by the hostess, Anne Robinson, who asks questions and evaluates the answers as right or wrong. The other participants in the quiz are nine contestants whose aim is to answer correctly as many questions as possible and bank as much money as they can. The quiz is divided into eight rounds. After each round the contestants have to decide who among them deserves to be voted off as the weakest link. The choice need not always follow the reality, especially towards the end of the quiz when the players strategically get rid of sometimes better players than themselves. In the end only two contestants remain and they have to play against each other in order to win the money that has been banked throughout the show. After each round the hostess spends some time chatting with the contestants. The purpose of this is to belittle and make fun of the contestant in question thus putting at risk their self-confidence. Anne Robinson has made her fame by being truly sarcastic, nasty and rude.

The relations among the participants in the quiz are strictly defined. The dominant speaker par excellence is Anne Robinson and if anyone of the contestants tries to endanger her dominant role, they are immediately punished by one of Anne's caustic remarks. When it comes to the relationships among the contestants, they are clearly subordinate in relation to Anne, but fight for dominance among themselves when Anne gives them the chance to speak and explain why they voted for a particular contestant as the weakest link.

The purpose to use The Weakest Link quiz for the analysis was primarily to show how intonation is used to express dominance, cooperativeness and non-cooperativeness among the contestants, their attitude to the topics of conversation and especially the expressive and attitudinal aspects of their speech which are extremely vital for the success of this show. 


\section{ATTITUDINAL APPROACHES TO THE STUDY OF INTONATION}

O'Connor and Arnold (1975) have developed a list of ten intonation patterns or tunes, as they call them. They vary in the degree of the pitch range they cover: some have a very broad pitch range, others have a narrower pitch range; in some the pitch movement is first rising and then falling, while others begin with a falling pitch movement which is later followed by the fall-rise tone. Each of the tunes has a number of meanings which often depend on the type of a syntactical structure they are used in, as well as on the context in which they occur. The main criticism of O'Connor and Arnold's model was that the intonation meanings are as diverse as the number and the types of situations they can occur in.

One of the first linguists to have shown interest in the intonation of the English language was Pike (1945). He developed a very comprehensive description in which he was also interested in intonation meanings and the speaker's attitude to the message as well as to the addressee. His description is based on four pitch levels and four tones which may begin on one and end on the other pitch level. Pike's intonation lexicon thus consists of 29 contours. In spite of the fact that Pike's model is even more comprehensive in the number of patterns than O'Connor and Arnold's, it is much less confusing in labelling the meanings. The only problem is that he does not make a distinction between the syntactic structure of an utterance and its attitudinal meaning. 'Non-finality' and 'question' are certainly not attitudes.

It seems almost impossible to develop a comprehensive intonation model which would account for a great variety of attitudinal meanings in a relatively simple and straightforward way. However, Tench (1996: 136) managed to summarize the main attitudinal meanings of tones and pre-tonic segments in English.

He distinguishes four tones (the fall, the rise, the fall-rise and the rise-fall) which can be neutral or marked depending on the informational and communicative intentions of the speaker, as well as the syntactic structure of the utterance. The attitudinal markedness of the tones is expressed by the height of the pitch range. Thus the fall and the rise pronounced in high pitch sound 'strong' and 'intense', whereas when pronounced in low pitch they sound 'mild' and 'non-committal'. If the rise-fall is pronounced high in pitch, it sounds even 'more intense' and 'stronger' than the high fall, but when it is pronounced with low pitch it sounds 'intensified and emotional'. The neutral form for the fall-rise is high pitch, while an attitudinally marked form is low with a 'strong contrastive and implicational' meaning.

Tench (1996: 137) also summarized the pre-nuclear pitch patterns, the so-called 'heads'. There are six heads: high, low, descending, ascending, stepping and glissando. They do not have their independent meanings but are closely associated with the tones. Thus the combinations of a high head before a rise and a low head before a fall are used primarily to highlight the immediately following information; the combinations of a high head before a fall and a low head before a rise express insistence or involvement on the part of the speaker; the combinations of descending and ascending heads with any tone sound warm and expecting 
response. Stepping and glissando heads, which can be either descending or ascending, express emphasis and forcefulness.

\section{DISCOURSE APPROACH TO THE STUDY OF INTONATION}

The analysis of discourse functions of different prosodic features was carried out by David Brazil and resulted in an intonation model different from the attitudinal ones in that it related communicative meanings and values to tones, keys and pitch sequences valid in all occurrences of these prosodic features (Brazil 1985).

In his work on discourse intonation, Brazil has proposed that certain relationships exist between tone units which are manifested by means of different prosodic elements, such as the choice of tone, key and termination. He distinguishes between two basic, unmarked tones, the fall and the fall-rise. The former is proclaiming, the latter referring. The term referring means that the fall-rise marks the matter of the tone unit as part of the shared, already negotiated, common ground occupied by the participants in an on-going interaction. The fall, in contrast, presents the matter as new, i.e. not yet part of the common ground, hence the term proclaiming.

In addition to the two unmarked tones, there are also two marked ones, the proclaiming rise-fall and the referring rise, which are used exclusively to express dominance in spoken interactions. Dominance can either refer to the social roles that the speakers exhibit, or, more commonly, to the control of the discourse that is held by one participant (often the current speaker) who can expect to be allowed to proceed uninterrupted to the end of the turn. It has to be pointed out that the dominant speaker can choose between the unmarked (non-dominant) and marked (dominant) tones. There are, however, types of discourse where the listeners expect the speakers to behave according to their dominant roles (e.g. doctor-patient, judge-witness, teacher-pupil interactions).

According to Brazil, the level tone does not exhibit any interactive nature. It is a tone which occurs normally in "ritualized or pre-coded speech" (Brazil 1995: 244). In spontaneous speech, the level tone is frequently used when speakers need time to plan ahead.

Brazil has also proposed that certain relationships exist between tone units. These are manifested by means of prosodic features which he has called key and termination. If tones exhibit certain pitch movements, then key and termination refer to the pitch level of the first (i.e. key) and the last (i.e. termination) pitch prominent syllables. Both, key and termination, can be realized at three different pitch levels: high, mid or low.

The communicative value of the high key is to present the matter expressed in the tone unit as being contrary to the expectations of the hearer. The low key, on the other hand, presents the matter as something which follows naturally from the previous matters and is in agreement with the hearer's expectations. The mid key expresses no special expectations on the part of the hearer, its function being only to add one piece of information to the other. 
The pitch level of the last prominent syllable, i.e. the nucleus, is called termination. Its communicative function is to signal the speaker's expectations with regard to the key of the following intonation unit. In other words, high termination anticipates high key, whereas mid termination anticipates mid key. Low termination does not set up any expectations regarding the key of the following tone unit.

The discourse functions of tone, key and termination are mainly to enhance lexical and grammatical cohesion and to achieve coherence in speech.

\section{THE ANALYSIS OF DISCOURSE AND ATTITUDINAL INTONATION MEANINGS IN THE WEAKEST LINK}

The analysis of The Weakest Link quiz had the following aims:

- to establish how cohesion is achieved within as well as across turn boundaries by means of different prosodic features;

- to establish which prosodic features add to the dominant role of Anne Robinson;

- to find out which prosodic features are used to achieve the sarcastic and condescending tone of voice.

The analysis was only auditory since we believe that people primarily react to what their ears can perceive and not to what a very detailed and minute acoustic analysis could show.

\subsection{Cohesion and coherence in speech}

The discourse structure of The Weakest Link quiz is the following:

1. Opening speech by Anne Robinson in which she briefly explains the main idea behind the quiz.

2. Short introductions by each individual contestant: name, age and in this case the studies and the university where they study.

3. Anne Robinson explains the rules of the game.

4. Anne Robinson announces the first round of questions with the phrase: Let's play the weakest link; in each round:

- $\quad$ Anne calls the contestant by the name and

- asks the question

- the contestant produces an answer

- Anne evaluates it by saying correct or by giving the correct answer herself

- Anne calls the next contestant

5. When the time is up, Anne informs the contestants about how much money they have banked.

6. Anne produces one sarcastic remark and tells the contestants to choose the weakest link by saying: It's time to vote off the weakest link.

7. While the contestants are busy deciding whom they are going to eliminate, a narrator informs the viewers which contestant was statistically the strongest and the weakest link, respectively. 
8. Voting over. It's time to reveal who you think is the weakest link is the phrase after which

9. the contestants show their boards with the names of the weakest links

10. Anne starts 'chatting' with the contestants asking them provocative questions related to their performance in the questioning round or to their appearances. Her remarks are usually unpleasant and test the contestants' self-confidence and alertness to respond to her.

11. Anne announces the weakest link.

12. The contestant who has been voted the weakest link walks from the podium.

13. The eliminated contestant comments the show and his fellow-contestants and predicts the next weakest link.

14. Anne announces the next round of questions. The same principle continues to the last round when the remaining two contestants compete against each other. They are given five questions and the one who answers more questions correctly is the winner.

15. Anne announces the winner

16. The show ends with Anne's closing remark: Join us again for The Weakest Link. Goodbye.

In order to establish the cohesive function of intonation within a turn, the best way is to look at Anne Robinson's opening speech, her explanation of the rules, as well as her recap of each questioning round.

In the opening speech Anne interchangeably uses the fall-rises and the falls which is according to Brazil's theory the way of achieving anaphoric and cataphoric references, respectively.

(1) The ' nine contestants in the $\searrow \nearrow$ studio here today / are $\searrow$ students. // They 'might think that makes them $\nearrow$ clever.// $\nearrow \nearrow$ We will find \out. // They are $\searrow \nearrow$ here to play for up to 10,000 pounds.// They $\uparrow$ don't $\nearrow$ know each other. // How $\searrow$ ever, / if they $\searrow \nearrow$ want that prize money, / they'll have to work as a \team. // \But / $\nearrow$ eight of them / will ' leave with $\searrow \nearrow$ nothing, / as $\nearrow \nearrow$ round by round we lose the $\searrow$ player / $\rightarrow$ voted / the $\uparrow$ weakest $\searrow$ link. // Let's \meet the team. $/ /^{1}$

It is clear that the fall-rise is often used to make reference to the shared knowledge between Anne, on the one hand, and the contestants as well as the viewers, on the other. It has to be mentioned that the picture on the screen is often an important point of reference. In addition, it has to be remembered that this is a well-known quiz, so the viewers and the contestants already know a lot about the structure and the rules of the quiz. Hence, the falls are used strictly only on those items which convey truly new information, such as, the fact that the contestants are students (in

\footnotetext{
${ }^{1}$ Table of symbols: the tones: \fall, $\nearrow$ rise, $\searrow \nearrow$ fall-rise, $\nearrow \searrow$ rise-fall, $\rightarrow$ level; the keys: $\downarrow$ low, $\uparrow$ high., $\searrow \searrow$ falling, $\nearrow \nearrow$ rising.
} 
contrast to other shows when the contestants come from all parts of the UK, have different occupations and belong to different age groups).

The decision which pieces of information are to be introduced as new or as old, depends on the speaker. It seems that Anne found it important to stress the fact that the contestants have to work as a team till the very end. Hence, the fall on that piece of information.

An interesting coherent link is established between the sentences: They 'might think that makes them $\nearrow$ clever.// $\nearrow$ We will find \out. // where the combination of a head and a rise in the first sentence is used to 'create expectancy' about what is to follow (O'Connor/Arnold, 1975: 63).

A similar exchange pattern of falls and fall-rises can be observed in the part where Anne is explaining the rules of the game:

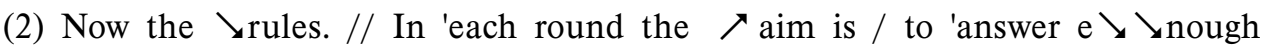
questions cor $\searrow \nearrow$ rectly / to reach your one $\searrow \nearrow$ thousand pound target / wi'thin the \time limit. // The $\searrow \nearrow$ fastest way / is to cre'ate a $\nearrow$ chain / of 'nine correct $\searrow$ answers. // 'Get your question $\nearrow$ wrong / and you $\searrow \nearrow$ break the chain / and 'lose all the $\searrow \nearrow$ money in that chain,/ \but / if you 'say the word $\uparrow \searrow$ BANK, /

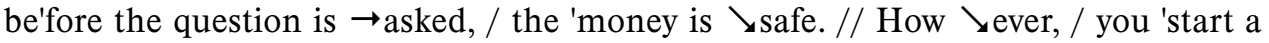

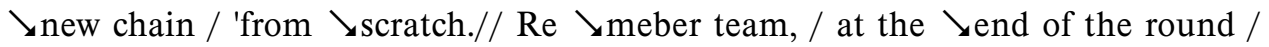

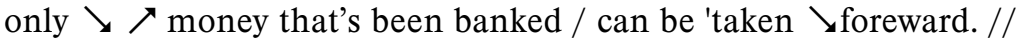

The important pieces of information are, in spite of the fact that they might be well-known to the contestants, pronounced as new information, i.e. with the falling tone. The reason is very straightforward: to remind the contestants how they should behave to earn as much money as possible and how to behave to avoid losing it.

The part of the show where cohesion is established by means of intonation, is at the end of each round when Anne briefly summarizes the contestants' performance in that round.

(3) And $\searrow \searrow$ in that $\searrow \nearrow$ first round, / you a $\rightarrow$ chieved / a 'rather sad 800

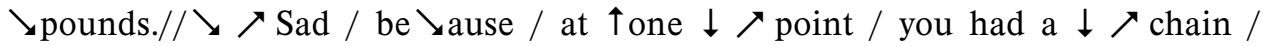
of \ten / cor \rect / $\downarrow \searrow$ answers.//

The above example is a typical example of how cohesion is achieved by means of tones when they are used on the same lexical item: the fall on the first sad introduces new information, the fall-rise on the second sad, establishes the anaphoric tie with the first sad and serves as an introduction to the explanation why the team performed badly.

The analysis of the question-answers sequences has shown two main features: one is the choice of tone, and the other, the choice of key. In questions which consist of an introductory part and the direct question. Anne uses the high key and the falling tone in that part of the question which directly asks the question: 
(4)

Anne: \Andrew. // An 'annual e $\nearrow$ vent / 'takes \place / †how many times a $\uparrow \searrow$ year?//

If the contestant's answer is correct, Anne evaluates it as such, using the low key and the fall:

Andrew: \Once.

Anne: Cor $\downarrow$ \rect.//

She continues the turn by calling the next contestant. For that purpose, she uses the high key and the fall:

(6)

Anne: Cor $\downarrow \searrow$ rect. // $\uparrow$ Katy. // Which 'two-letter $\nearrow$ word / can $\rightarrow$ mean / out of $\nearrow$ bed / in 'residence at uni $\nearrow$ versity / or \in / an ex'cited \state?//

If the contestant's answer is wrong, Anne corrects it by using the high key and the fall:

Katy: \In

Anne: $\uparrow \searrow$ Up. $/ / \uparrow \searrow$ Nathan. $/ / \ldots$

\subsection{Dominance in speech}

According to Brazil's theory, the dominant speaker can, in addition to the two neutral tones, also use their marked variants, i.e. the proclaiming rise-fall and the referring rise. It is evident that the only dominant speaker in The Weakest Link quiz is its hostess, Anne Robinson. The analysis has shown that she quite often uses the dominant variants of the proclaiming and referring tones.

There are two phrases which function as frames between different parts of the quiz. These are: Time's up and Voting over.

The phrase Time's up is six times pronounced with the high key and the high rise:

(8) $/ / \uparrow$ Time's $\uparrow \nearrow$ up//

and twice with the high key and the high fall:

(9) $/ / \uparrow$ Time's $\uparrow$ \up//.

Due to the fact that the end of the round is always indicated by a sound signal, it is not surprising to hear a referring tone. What is more interesting is that Anne's 
choice is the dominant referring tone (i.e. the rise). This clearly indicates that she is very conscious of her dominant role as the hostess of the quiz and finds it necessary to emphasise it as often as possible. Her decision to use the fall twice can also be explained in a similar way: 'in case you are not aware of it, let me tell you that the time's up'.

Very similarly, the phrase Voting over was four times pronounced with the high key and the high rise:

(10) $/ / \uparrow$ Voting $\uparrow \searrow$ over $/ /$

and three times with the high key and the rise-fall:

(11) $/ / \uparrow$ Voting $\uparrow \nearrow$ \over $/ /$

The reasons for these choices are similar as for examples (8) and (9) with the only difference that in case of example (11) Anne has decided to use the dominant variety of the proclaiming tone, thus making her dominant status even more clear.

\subsection{Ways of expressing sarcasm and condescension by means of different prosodic features}

It has already been pointed out that the fil rouge of the quiz is to belittle the contestants in order to test their self-confidence and concentration. It is an endurance test which is well-described in Anne's phrase, "You have to be ruthless to be rich".

Anne's bitter comments on behalf of the contestants occur in her chats with them after each round of questions. Some of her comments regard the knowledge of the contestants, some their physical appearance and speech. The contestants have to show how well they can endure Anne's sarcasm.

The analysis of Anne's caustic remarks has shown that the prevailing tone is the rise-fall. She uses it three times when she announces the strongest link in a particular round:

(12) We'll start with the strongest link from the last round. // That's $\nearrow \searrow$ Katy. //

(13) We'll start with the strongest link from the last round. // That's $\nearrow \searrow$ Ben. //

(14) We'll start with the strongest link from the last round. // That's $\nearrow \searrow$ Stuart.//

The attitude expressed is that of sarcasm and disbelief in O'Connor and Arnold's terminology, while Brazil would explain this marked variant of a proclaiming tone as information that is new to both, the speaker and the addressee, hence its local attitudinal meaning of sarcasm and disbelief.

Two occurrences of the rise-fall preceded by the high key, which makes the speaker sound 'complacent, self-satisfied, smug, challenging or censorious' (O'Connor/Arnold 1975: 79), were used by Anne in her comments on the contestants' general and individual performance in answering the questions: 
(15) // Who is $\uparrow$ clearly educated beyond their in $\nearrow$ \telligence?//

(16) // $\uparrow$ Which uni $\nearrow$ \versity,$/$ is $\uparrow$ missing its $\nearrow$ \idiot?//

(17) $/ / \uparrow \searrow$ Say Ben, / you 'quite a little $\nearrow \searrow$ clever clogs / in $\nearrow \searrow$ that round, / $\nearrow \searrow$ weren't you?//

The second most frequently used intonation pattern to express 'categorical, weighty, judicial' attitudes, but also 'detached, flat and unsympathetic' (O'Connor/Arnold 1975: 48-50) is the combination of the high key and the low fall $(18,19)$ or just the low fall (20):

(18)

Anne: Stuart. What are you smiling at?

Stuart: Your lovely face, Anne. I can't resist myself. I'm sorry.

Anne: //You $\uparrow$ can't resist your $\downarrow \searrow$ self,/ or you $\uparrow$ can't resist $\downarrow \searrow \mathrm{me}$ ?//

(19)

Anne: // What $\downarrow \searrow$ qualities do you have / that would $\uparrow$ make anyone think you'd make a good $\mathrm{T} \downarrow \searrow \mathrm{V}$ presenter.?//

Ben: I study zoology, Anne.

Anne: // $\downarrow$ Why?//

\section{CONCLUSION}

The aim of this paper was to show that intonation is an inherent part of language whose main communicative functions are grammatical, discourse and attitudinal. Although there is a great deal of disagreement among the linguists which of the three functions is more important, we have to conclude that they are equally important but above all intertwined. The linguistic function is perhaps easiest to determine, whereas the other two are more elusive.

In order to evaluate the attitudinal and discourse meanings of intonation as described by O'Connor and Arnold (1975) and Brazil (1997), respectively, we decided to analyse a very popular quiz show whose fil rouge are ruthlessness, sarcasm and condesc

The analysis has shown that discourse and attitudinal meanings of intonation are strongly intertwined. This is understandable since the pragmatic value of speech depends on the speakers' perception of the context of interaction and their understanding of the lexis and grammar. Thus it has been confirmed that the fall-rise and the fall are used to express the anaphoric and cataphoric reference respectively, and that the high key is used to express contrast, in our case to correct contestants' wrong answers. If the answer is correct, it is accepted as such by means of the falling tone and the low key.

Tones are also very important in conveying the dominant status of the speaker. In our analysis the hostess of the show constantly reminds the contestants of the fact 
by using rising or rise-falling tones. Sarcasm and condescension are the two prevailing attitudes in The Weakest Link quiz. They are expressed by means of two pitch patterns: the rise-fall or the high key followed by the low fall.

In conclusion, we can safely claim that both, the attitudinal and discourse approaches to the study of intonation are relevant. We believe that the future of intonation studies is to establish some universal attitudinal and discourse functions which are common to a number of other European languages.

\section{Bibliography}

BraziL, D. (1997) The Communicative Value of Intonation in English. Cambridge: Cambridge University Press.

Crystal, D./D. DAVY (1975) Advanced Conversational English. London: Longman.

Couper-Kunlen, E. (1986) English Prosody. London: Edward Arnold.

Couper-Kunlen, E. (1993) English Speech Rhythm. Form and Function in Everyday Verbal Interaction. Amsterdam and Philadelphia: Benjamins.

Couper-Kuhlen, E./M. Selting (eds.) (1996) Prosody in Conversation. Cambridge: Cambridge University Press.

Halliday, M. A. K. (1976) Intonation and Grammar in British English. The Hague: Mouton. O'CONNoR, J. D./G. F. ARNold (1975) Intonation of Colloquial English. London: Longman.

PIKE, K. L. (1945) The Intonation of American English. Ann Arbor: University of Michigan Press. TENCH, P. (1996) The Intonation Systems of English. London: Cassell.

Wichmann, A. (2000) Intonation in Text and Discourse: Beginnings, Middles and Ends. London: Longman.

\section{Povzetek \\ INTONACIJA: NAJMOČNEJŠI ČLEN V KVIZU NAJŠIBKEJŠI ČLEN}

Glavna tema članka je angleškegi kviz, imenovan The Weakest Link, ki ga redno oddaja britanska TV hiša BBC Prime. Kviz je prepoznaven po ponižujočih in sarkastičnih komentarjih voditeljice kviza, Anne Robinson, s katerimi preizkuša psihično trdnost in vzdržljivost tekmovalcev. Tekmovalci so rivali, ki pa si morajo pomagati, da bi zaslužili čim več denarja. Ko pa se odločajo za to, kdo med njimi bo najšibkejši člen, so drug do drugega enako brezobzirni, kot je do njih Anne Robinson. Lahko rečemo, da kviz posega v najtemnejše kotičke človeške narave, jezik pa mu je pri tem glavna opora.

Namen članka je analizirati besedilno zgradbo kviza z namenom ugotoviti, katere sporočilne vrednosti k dokončni podobi oddaje prispeva stavčna intonacija. Članek ugotavlja, da stavčna intonacija igra tri vloge: jezikovno, besedilno in pragmatično. Slednjo poslušalec zaznava kot paleto različnih stališč in čustvenih pomenov, ki naj bi jih posamezni intonacijski poteki imeli. Vse tri sporočilne vrednosti intonacije se med seboj prepletajo. Analiza oddaje The Weakest Link je pokazala, kako različni tonski poteki in glasovne lege izražajo govorčev odnos med udeleženci v govornem položaju ter njihov odnos do vsebine govora. Analiza je pokazala tudi, da stavčna intonacija igra pomembno vlogo pri zagotavljanju kohezije in koherence govora. 